\title{
7. Addressing COVID-19 impacts on agriculture, food security, and livelihoods in India
}

\section{S. Mahendra Dev}

India took early action to limit the spread of COVID-19, ordering a 21-day nationwide lockdown for its population of 1.3 billion people starting March 25. Subsequently the lockdown was extended three more times before May 31. The unlocking of India began June 1, except in containment zones. The novel coronavirus has spread widely in India and the number of reported infections is 217,000 , with relatively few deaths, at 6,075, as of June 4. However, as COVID-19 cases are increasing fast, there is great concern about the disease's potential spread and impact. India has to be ready for a possible surge. The government views the pattern of the spread of COVID-19 as similar to the 2009 H1N1 influenza pandemic, meaning the spread is unlikely to be uniform. It is concentrated in a few big cities and states and its spread is less in rural areas and smaller towns and cities.

The lockdown of India for more than two months helped in limiting the health crisis, but - as in other countries - the complete shutdown of all economic activities except essential services has created an economic crisis and misery for the poor, with massive job losses and rising food insecurity.

The economic shock has been much more severe for India, for two reasons. First, pre-COVID-19, the economy was already slowing down, compounding existing problems of unemployment, low incomes, rural distress, malnutrition, and widespread inequality. Second, India's large informal sector is particularly vulnerable. Out of the national total of 465 million workers, around $91 \%$ (422 million) were informal workers in 2017-2018. Lacking regular salaries or incomes, these agricultural, migrant, and other informal workers would be hardest hit during the lockdown period. Here, I focus on the likely impacts on agriculture, supply chains, food and nutrition security, and livelihoods.

\section{Agriculture and supply chains}

COVID-19 is disrupting some activities in agriculture and supply chains. Preliminary reports show that the lack of available migrant labor is interrupting some harvesting activities, particularly in northwest India where wheat and pulses were harvested. There are disruptions in supply chains because of transportation problems and other issues. Prices have declined for wheat, vegetables, and other crops, yet consumers are often paying more. Media reports show that the closure of hotels, restaurants, sweet shops, and tea shops during the lockdown is already depressing milk sales. Meanwhile, poultry farmers have been badly hit due to misinformation, particularly on social media, that chickens are carriers of COVID-19. 
Some measures required to keep the agricultural sector and supply chains working smoothly are listed here:

1. The government has correctly issued lockdown guidelines that exempt farm operations and supply chains. But implementation problems leading to labor shortages and falling prices should be rectified.

2. Keeping supply chains functioning well is crucial to food security. It should be noted that 2 million to 3 million deaths in the Bengal famine of 1943 were due to food supply disruptions - not a lack of food availability.

3. Farm populations must be protected from the coronavirus to the extent possible by testing for the virus and practicing social distancing.

4. Farmers must have continued access to markets. This can be a mix of private markets and government procurement.

5. Small poultry and dairy farmers need more targeted help, as their pandemic-related input supply and market-access problems are urgent.

6. Farmers and agricultural workers should be included in the government's assistance package and any social protection programs addressing the crisis.

7. As lockdown measures have increased, demand has risen for home delivery of groceries and e-commerce. This trend should be encouraged and promoted.

8. The government should promote trade by avoiding export bans and import restrictions.

\section{Using social safety nets as a bridge between health shock and economic shock}

The lockdown has choked off almost all economic activity. In urban areas, this has led to the widespread loss of jobs and incomes for informal workers and the poor. Estimates by the Centre for Monitoring Indian Economy show that unemployment shot up from 8.4\% in mid-March to 27\% throughout April. In urban areas, unemployment was around 30\% in April. There was a loss of 122 million jobs in April compared to the employment level in 2019. Only in the first week of June, the unemployment rate declined to $23 \%$. The shutdown has caused untold misery for informal workers and the poor, who lead precarious lives and face hunger and malnutrition.

The best way to address this urgent need is to use social safety nets extensively to stabilize their lives with food and cash.

The Indian government has responded quickly to the crisis and announced a $\$ 22$ billion relief package, which includes food and cash transfers. Several state governments have announced their own support packages. 
The central government's relief package, called Pradhan Mantri Garib Kalyan Yojana (Prime Minister's plan for well-being of the poor), is aimed at providing safety nets for those hit hardest by the COVID-19 lockdown. However, it is inadequate in the face of the enormous scale of the problem. Nobel Prize economists Esther Duflo and Abhijit Banerji say that the government should have been much bolder with the package's social transfer schemes. The $\$ 22$ billion in spending is only $0.85 \%$ of India's GDP.

In the middle of May, the central government announced a Rs. 20.9 trillion ( $\$ 279$ billion) package $10 \%$ of GDP - covering, among others, agriculture, informal workers, and medium, small, and micro enterprises (MSME). One of the criticisms of the package is that many of its measures are related to credit availability and long-term reforms. These measures could be useful in the medium and long term. The real fiscal stimulus is only $1 \%$ of GDP. The poor and vulnerable need immediate help.

Below are some further measures needed in addition to the government package:

- Food and nutrition security. Government warehouses are overflowing with 71 million tons of rice and wheat. In order to avoid exclusion errors, it is better to offer universal coverage of distribution in the next few months. Nutrition programs like Integrated Child Development Services (ICDS), mid-day meals, and Anganwadis (rural childcare centers) should continue to work as essential services and provide rations and meals to recipients at home. Eggs can be added to improve nutrition for children and women. Several state governments have started innovative programs to help informal workers and the poor. For example, the Kerala government is providing meals with diversified diets at the doorsteps of households.

- Cash transfers. Unemployed informal workers need cash income support. The government has provided Rs.500 (\$6.60) per month to the bank accounts of 200 million women via the Jan Dhan financial inclusion program. But this too is insufficient. A minimum of Rs.3000 ( $\$ 40)$ per month in cash transfers is needed for the next three months.

- Migrant workers. There are about 40 to 50 million seasonal migrant workers in India. In recent days, global media have broadcast images of hundreds of thousands of these migrant workers from several states trudging long distances on highways; some walked more than 1,000 kilometers to return to their home villages. These workers should be given both cash transfers and nutritious food.

COVID-19 is an unprecedented challenge for India; its large population and the economy's dependence on informal labor make lockdowns and other social distancing measures hugely disruptive. The central and state governments have recognized the challenge and responded aggressively - but this response should be just the beginning. India must be prepared to scale it up as events unfold, easing the economic impacts through even greater public program support and policies that keep markets functioning. 